CHRONIC OBSTRUCTIVE PULMONARY DISEASE

\title{
Evidence for a link between mortality in acute COPD and hospital type and resources
}

\section{M Roberts, S Barnes, D Lowe, M G Pearson, on behalf of the Clinical Effectiveness Evaluation Unit, Royal College of Physicians and the Audit Subcommittee of the British Thoracic Society}

See end of article for authors' affiliations

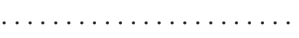

Correspondence to: Dr C M Roberts,

Department of Respiratory Medicine, Whipps Cross University Hospital London E1 1 1NR, UK; Michael.Roberts@ whippsx.nhs.uk
Background: The 1997 BTS/RCP national audit of acute care of chronic obstructive pulmonary disease (COPD) found wide variations in mortality between hospitals which were only partially explained by known audit indicators of outcome. It was hypothesised that some of the unexplained variation may result from differences in hospital type, organisation and resources. This pilot study examined the hypothesis as a factor to be included in a future national audit programme.

Methods: Thirty hospitals in England and Wales were randomly selected by geographical region and hospital type (teaching, large district general hospital (DGH), small DGH). Data on process and outcome of care (death and length of stay) were collected retrospectively at 90 days on all prospectively identified COPD admissions over an 8 week period. Each centre completed a questionnaire relating to organisation and resources available for the care of COPD patients.

Results: Eleven teaching hospitals, nine large DGHs, and 10 small DGHs provided data on 1274 cases. Mortality was high (14\%) with wide variation between centres (IQR 9-19\%). Small DGHs had a higher mortality (17.5\%) than teaching hospitals (11.9\%) and large DGHs (11.2\%). When corrected for confounding factors, an excess of deaths in small DGHs was still observed (OR $1.56(\mathrm{Cl} 1.04$ to 2.35)) v teaching hospitals. Analysis of resource and organisational factors suggested higher mortality was associated with fewer doctors (OR 1.5) and with fewer patients being under the care of a specialist physician (OR 1.8). Small DGHs had fewest resources.

Conclusion: Significant differences in mortality may exist between hospital types. The findings justify further study in a proposed national audit.
A cute exacerbations of chronic obstructive pulmonary disease (COPD) are responsible for more than $6 \%$ of all admissions and $10 \%$ of acute medical admissions in the UK $^{1}$ and have a high mortality. ${ }^{2}$ The 1997 British Thoracic Society (BTS)/Royal College of Physicians (RCP) audit of acute hospital care of COPD showed a 90 day mortality of $14 \%$ and observed wide variation between hospitals. ${ }^{3}$ We hypothesised that some of the variability in outcome may be the result of hospital type and size, with organisation of care and available resources contributing to these differences. We examined this hypothesis by auditing the outcome of death at 90 days following acute admission for COPD in hospitals subdivided by type and size. The results of this study were to inform proposals for a future national audit programme for the UK.

\section{METHODS}

All acute hospitals in England and Wales were identified as eligible to participate. Teaching hospitals were classed separately with the sample selected at random. District general hospitals (DGHs) were classed as large ( $>600$ beds) or small ( $<600$ beds) according to Department of Health criteria, and were grouped into five regions with random sampling of large and small hospitals from each region. A refusal generated an invitation to the next hospital on the list until 30 hospitals were recruited. Each centre identified a consultant respiratory lead for the project. Cases of acute COPD (physician made diagnosis) admitted to hospital were identified prospectively over an 8 week period and data were collected retrospectively at 90 days following admission. The audit proforma* included 23 process items suggested by previous audit as valuable ${ }^{4}$ or by the BTS guidelines ${ }^{5}$ as essential management interventions, and two outcome measures (death and length of stay). Deaths were recorded as in-hospital or after discharge. The accuracy of the data was checked by an external auditor, duplicating entries at 21 of the participating centres to give 293 cases in all.

A separate questionnaire recorded details of available resources and organisation at each centre*. Both sets of data were entered onto a modified access database (Microsoft Inc, Redmond, USA) and analysed centrally using SPSS Version 11 (SPSS (UK) Ltd, Woking, UK).

\section{Statistical methods}

The reliability of the data was checked by comparing the duplicate data using the Kappa statistic for which values of 0.60 and above represents "good" agreement between hospital and external auditors. Kappa statistics were 0.59 for performance status, 0.67 for the recording of blood urea, and 0.99 for blood gases on admission. Agreement on actual urea values was achieved for $90 \%$ of cases and on $\mathrm{pH}$ values for $95 \%$. There was agreement on the date of death in all but four cases.

Binary logistic regression was used to compute odds ratios (ORs) and confidence intervals (CI) for mortality in small and large DGHs relative to teaching hospitals, corrected for the known important indicators of increased mortality, performance status, arterial blood $\mathrm{pH}$, and blood urea. $^{3}$

*Available at www.rcplondon.ac.uk/college/ceeu/ceeu_copd_ prev.htm/. 


\begin{tabular}{|c|c|c|c|}
\hline & $\begin{array}{l}11 \text { Teaching hospitals } \\
\text { (461 cases) }\end{array}$ & $\begin{array}{l}9 \text { Large DGH } \\
\text { (357 cases) }\end{array}$ & $\begin{array}{l}10 \text { Small DGH } \\
\text { (456 cases) }\end{array}$ \\
\hline In-hospital death & $4.8 \%(n=22)$ & $9.0 \%(n=32)$ & $12.3 \%(n=56)$ \\
\hline OR & - & 2.00 & 2.79 \\
\hline Corrected OR* $(95 \% \mathrm{Cl})$ & - & 2.91 (1.55 to 5.49 ) & $3.22(1.81$ to 5.73$)$ \\
\hline Death at 90 days & $11.9 \%(n=55)$ & $11.2 \%(n=40)$ & $17.5 \%(n=80)$ \\
\hline OR & - & 0.93 & 1.57 \\
\hline Corrected OR* $(95 \% \mathrm{Cl})$ & - & 1.11 (0.69 to 1.78$)$ & 1.56 (1.04 to 2.35$)$ \\
\hline \multicolumn{4}{|c|}{ Consultant staff (respiratory and non-respiratory) per 10 patients } \\
\hline $\begin{array}{l}\leqslant 3.9 \text { WTE } \\
>3.9 \text { WTE }\end{array}$ & $\begin{array}{l}1 \text { hospital } \\
8 \text { hospitals }\end{array}$ & $\begin{array}{l}4 \text { hospitals } \\
4 \text { hospitals }\end{array}$ & $\begin{array}{l}8 \text { hospitals } \\
0 \text { hospitals }\end{array}$ \\
\hline \multicolumn{4}{|c|}{$\%$ of acute COPD patients seen by respiratory specialist } \\
\hline $\begin{array}{l}\leqslant 45 \% \\
>45 \%\end{array}$ & $\begin{array}{l}5 \text { hospitals } \\
3 \text { hospitals }\end{array}$ & $\begin{array}{l}1 \text { hospital } \\
6 \text { hospitals }\end{array}$ & $\begin{array}{l}4 \text { hospitals } \\
1 \text { hospital }\end{array}$ \\
\hline \multicolumn{4}{|c|}{ Non-invasive BiPaP or NiPPV available } \\
\hline Yes & 10 hospitals & 6 hospitals & 6 hospitals \\
\hline No & 1 hospital & 2 hospitals & 3 hospitals \\
\hline
\end{tabular}

\section{RESULTS}

Forty one hospitals were invited to participate; 27 accepted and three further sites volunteered to enter the study. All 30 returned data. These were 11 teaching hospitals, nine large DGHs, and 10 small DGHs. There were 1274 patients of mean age 72.1 years and mean forced expiratory volume in l second $\left(\mathrm{FEV}_{1}\right) 41 \%$ predicted $(\mathrm{n}=405) ; 56 \% \quad(\mathrm{n}=716)$ were men. Mortality at 90 days was $14 \%$ overall (in-hospital mortality 9\%) with wide variation between centres (IQR 9$19 \%$ ). Table 1 shows mortality rates by hospital type. The ORs of mortality for large and small DGHs are relative to mortality in teaching hospitals.

Median (range) summary statistics for the three main patient related outcome indicators of death by hospital type were:

- poor performance status (PS 4/5): teaching hospital $28 \%$ (8-39), large DGH 21\% (12-29), small DGH 38\% (13-57), $\mathrm{p}=0.57$ (Kruskall-Wallis);

- blood urea: teaching hospital $6.1 \mathrm{mmol} / \mathrm{l}$ (5.3-8.2), large DGH $6.1 \mathrm{mmol} / \mathrm{l}$ (5.5-6.8), small DGH $6.5 \mathrm{mmol} / \mathrm{l}$ (5.17.2), $\mathrm{p}=0.46$ (Kruskall-Wallis);

- mean arterial pH: teaching hospital 7.39 (7.33-7.43), large DGH 7.40 (7.35-7.40), small DGH 7.40 (7.35-7.42), $\mathrm{p}=0.81$ (Kruskall-Wallis).

Odds ratios adjusting for performance status, arterial blood $\mathrm{pH}$, and blood urea are also shown and suggest that, although the performance status of patients in small DGHs was worse than in the other two types of hospital, it did not account for the higher mortality observed.

Hospitals were divided into two groups by median levels of the resource and organisational factors recorded. Significant differences in the 90 day mortality rate were seen for (1) the number of doctors involved in the emergency care of medical cases admitted (OR 1.5 for fewer than 3.9 doctors per 10 COPD patients), (2) physician estimated proportion of patients cared for by respiratory specialists (OR 1.8 for $<45 \%$ ), and (3) availability of non-invasive ventilation (OR 1.5 if unavailable). All three factors were related to the type of hospital (table 1), with small DGHs having fewer doctors and fewer patients cared for by a respiratory specialist and being less likely to offer an NIV service.

\section{DISCUSSION}

This pilot audit suggests that mortality may be lower in larger hospitals and that the organisation of care and resources available for that care could be important factors in such a difference in outcome. Previous studies of acute care of COPD have identified a number of patient factors that determine outcome. ${ }^{36}$ Hospitals cannot influence the severity of illness or debility of patients before admission, but can plan to manage patients after admission. The better survival in teaching and larger hospitals is in keeping with other recent studies from North America examining outcomes in other areas of medical practice. ${ }^{7-9}$ An assessment of overall mortality in UK hospitals concluded that better staffing levels were associated with better outcome. ${ }^{10}$ While these observations have been reported and suggestions made that resource issues are important determinants of outcome, little supportive evidence has been provided.

We acknowledge that there are limitations to this study. This was a pilot study that examined a small number of hospitals. Data collection in some hospitals may have been incomplete and some inaccuracies in retrospective audits are inevitable. However, when checked by the external auditor, the reproducibility of the data was reasonably good. Some centres contributed larger numbers to the study than others, thereby weighting the results. The level of analysis reflects the nature of this pilot and, within a national audit, a more detailed interrogation of within and between hospital variation within the data set will need to be undertaken. Notwithstanding these limitations, the data provided here show consistency and face validity.

Hospital type and size were related in this pilot, with fewer doctors allocated to medical care per 10 COPD admissions and less than $45 \%$ of patients allocated to care by specialist respiratory physicians. Availability of more doctors and specialist care were associated with better outcome. While these individual resources are not necessarily the reason for improved outcome, they are an indicator of the more complex organisational and resource issues that constitute a teaching hospital. Donabedian ${ }^{11}$ described the three linked components that audit should address-organisation of care, processes of care, and outcome-and suggested that good organisation leads to better process and then to better outcomes. The national audits of stroke care have shown that better organisation is linked to better process, ${ }^{12}$ and improving the "time to needle" for myocardial infarction thrombolysis is driving better organisation/resources for patients arriving at hospital and dramatic improvements have been achieved. ${ }^{13}$

This pilot study suggests that some of the observed variance in mortality between hospitals may be due 
to organisational factors that are within the control of the health service. We conclude that this finding is of sufficient importance to warrant further investigation as part of a proposed national audit of the acute care of COPD.

\section{Authors' affiliations \\ C M Roberts, S Barnes, D Lowe, M G Pearson, Clinical Effectiveness Evaluation Unit, Royal College of Physicians and the Audit Subcommittee} of the British Thoracic Society, London, UK

\section{REFERENCES}

1 Ashton CM, Ferguson JA, Goldacre MJ. In patient workload in medical specialities. Q J Med 1995;88:661-72.

2 Anto JM, Vermeire $P$, Vestibo J, et al. Epidemiology of chronic obstructive pulmonary disease. Eur Respir J 2001;17:982-4.

3 Roberts CM, Lowe D, Bucknall CE, et al. Clinical audit indicators of outcome following admission to hospital with acute exacerbation of chronic obstructive pulmonary disease. Thorax 2002;57:137-41.
4 Roberts CM, Ryland I, Lowe D, et al. Audit of acute admissions of COPD: standards of care and management in the hospital setting. Eur Respir $J$ 2001;17:343-9.

5 British Thoracic Society. BTS guidelines on the management of COPD. Thorax 1997;52(Suppl 5):S1-28.

6 Almagro P, Calbo E, Ochoa de Echaguen A, et al. Mortality after hospitalisation for COPD. Chest 2002;121:1441-8.

7 Chaudhry R, Goel V, Sawka C. Breast cancer survival by teaching status of the initial treating hospital. Can Med Assoc J 2001;164:183-8.

8 Khuri SF, Naijar SF, Daley J, et al. Comparison of surgical outcomes between teaching and nonteaching hospitals in the Department of Veterans Affairs. Ann Surg 2001;234:370-83.

9 Polanzyk CA, Lane A, Coburn M, et al. Hospital outcomes in major teaching, minor teaching and non-teaching hospitals in New York State. Am J Med 2002;112:255-61.

10 Jarman B, Gaults S, Alves B, et al. Explaining differences in English hospital death rates using routinely collected data. BMJ 1999;318:1515-20.

11 Donabedian A. Evaluating the quality of medical care. Milbank Mem Fund Q 1966;44(Suppl): 166-206.

12 Rudd AG, Irwin P, Rutledge Z, et al. Regional variation in stroke care in England, Wales and Northern Ireland: results from the national sentinel audit of stroke. Clin Rehab 2001;15:562-72.

13 Birkhead J, Walker L, Norris R, et al. National audit of myocardial infarction: a new development in the audit process. J Clin Excellence 2003 (in press).

\section{LUNG ALERT}

Energy intake and weight are increased by antibiotics in children with cystic fibrosis $\Delta$ Béghin L, Gottrand F, Michaud L, et al. Impact of intravenous antibiotic therapy on total daily energy expenditure and physical activity in cystic fibrosis children with Pseudomonas aeruginosa pulmonary exacerbation. Pediatr Res 6 Aug 2003 (epub ahead of print)

A nti-Pseudomonas antibiotics have previously been shown to improve nutritional status in patients with cystic fibrosis, although the exact mechanism for this is unclear. In this prospective study 16 children of mean age 12.1 years with cystic fibrosis and chronic Pseudomonas aeruginosa colonisation were studied during and after a pulmonary exacerbation. Before a 2 week course of home intravenous antibiotics, aspects of their energy intake and expenditure were measured and body composition analysed to derive fat and fat free masses. Energy intake was measured with detailed 1 week food records analysed by a dietician. Resting energy expenditure was calculated by measuring oxygen consumption and carbon dioxide production. Total energy expenditure was calculated using heart rate monitoring calibrated against indirect calorimetry and 24 hour diaries of physical activity were kept. These measures were repeated 5-10 days after the end of the antibiotic course.

Following antibiotic treatment, both energy intake and weight were increased by $1.9 \%$ and physical activity was increased by $9.3 \%$. Total energy expenditure was similar before and after antibiotics. Resting energy expenditure increased during exacerbations with Pseudomonas aeruginosa and was significantly decreased by $4.1 \%$ after antibiotic treatment.

The authors suggest that an increase in weight and energy intake following antibiotic treatment directly promotes physical activity in children with cystic fibrosis and that this may have beneficial effects on their lifestyles.

S D West

Specialist Registrar, Oxford Centre for Respiratory Medicine, Oxford, UK sophie@west66.freeserve.co.uk 